\title{
LA TEODICEA EXISTENCIAL EN LEIBNIZ*
}

Alberto Sánchez León

* Artículo publicado en Mayéutica, ISSN 0210-2900, Vol. 33, № 76, 2007, pags. 479-495. 


\section{ÍNDICE}

Pág.

I. Introducción: Breve boceto del pensamiento leibniciano 3

II. La demostración de Dios por las verdades eternas

a) Punto de partida: la verdad eterna

b) Núcleo de la prueba: el principio de razón suficiente 6

c) Punto de llegada $\quad 8$

III. La armonía preestablecida para demostrar la existencia de Dios 9

a) Punto de inicio: la armonía preestablecida $\quad 9$

b) Desarrollo de la prueba $\quad 10$

c) Punto de llegada: Dios armónico y armonizante 12

IV. El argumento de la contingencia $\quad 12$

a) El punto de inicio: los seres contingentes 13

b) El principio de razón suficiente como condición de la prueba. Dios como Causa sui 15

c) Conclusión de la prueba 15

V. La prueba ontológica 16

VI. El argumento modal 18 


\section{Introducción: Breve boceto del pensamiento leibniciano.}

Gottfried Wilhelm Leibniz (1646-1716) puede ser considerado como un erudito universal: diplomático, jurista, historiador, matemático, físico y filósofo en una sola persona.

En lógica se convierte, por medio de la idea del cálculo, en el precursor de la lógica moderna: las ideas generales, tan simples como sea posible, se tienen que poder expresar con símbolos universales que estarán combinados con términos inteligibles. La finalidad es convertir los errores futuros en "errores de cálculo" y resolver las cuestiones en disputas mediante el cálculo.

Una parte esencial de la filosofía de Leibniz es la solución que ofrece a diversos problemas metafísicos mediante el concepto de mónada. La sustancia, al contrario que Descartes, no puede ser extensa, pues entonces sería divisible. De ahí que el criterio de la sustancia sea su acción, su fuerza. Leibniz denomina mónadas ${ }^{l}$ a esos puntos de fuerza. "Las mónadas son por tanto, los verdaderos átomos de la naturaleza, y en una palabra, los elementos de las cosas".

Estas sustancias elementales muestran las siguientes características:

- No tienen forma, pues ello implicaría su divisibilidad.

- En tanto que sustancias, no tienen ni comienzo ni fin.

- Son individuales: ninguna mónada es idéntica a otra.

- En tanto que seres independientes no tienen ventanas. Ninguna sustancia o determinación puede obrar saliendo de ellas o entrando en ellas.

Sin embargo están sometidas a un continuo proceso de cambio interior: un impulso interior hacia el perfeccionamiento, la denominada apetición, que efectúa la transición continua de un estado a otro. Leibniz llama a esos estados percepciones.

Estas informaciones y su programa indican la conexión de una mónada individual con todas las demás mónadas del mundo, como un punto en el que se reúnen infinidad de ángulos.

Dado que una mónada carece de ventanas, y a pesar de ello, está relacionada con todas las demás mónadas, hay que suponer que cada mónada es un espejo viviente, capaz de actividad interior, que representa el universo desde su punto de vista. De ello se sigue que cada mónada conoce el estado de cada una de las demás, aunque no es consciente de ello. Leibniz distingue varios grados de percepción: la mónada simple, la denominada mónada desnuda, que contiene todas las informaciones sobre el estado de todas las demás, pero no es consciente de ello. A diferencia de esto, en la apercepción, la percepción va

\footnotetext{
${ }^{1}$ Este término no es original de Leibniz, antes lo había usado Giordano Bruno que a su vez lo había tomado de Plotino.
} 
acompañada de la conciencia de ese estado.

De este modo, resulta un continuum que va desde la materia hasta el espíritu reflexivo del hombre pasando por el alma animal. El filósofo de Hannover habla por eso de la capacidad limitada de los animales basada en la experiencia, al igual que acepta en el hombre una inconsciencia: las petites (exiguas) perceptions.

Leibniz explica la cooperación de todas las mónadas mediante la armonía preestablecida. Las mónadas se agrupan en asociaciones, en agregados. El modelo de esto es el organismo: "Una mónada central se rodea de infinidad de otras y actúa como su entelequia".

Además, y como regla general, cada mónada está en relación con cada una de las otras. Como las mónadas carecen de ventanas, pero cada una coopera con cada una de las otras, Dios tiene que haber dispuesto el mundo de tal manera que concuerden los estados y las perspectivas de todas las mónadas.

La imagen de los relojes es la más conocida de Leibniz, y mediante ella se aplica la armonía preestablecida a la relación entre el cuerpo y el alma. La armonía preestablecida no sólo resuelve el problema de la relación cuerpo y alma, sino que en el fondo es el núcleo del sistema de Leibniz. Dios ha creado desde un principio todas las mónadas de tal manera que están en armonía entre ellas. Según R. Specht, la sucesión de las percepciones en las mónadas individuales, su programa por así decirlo, ha sido fijado por Dios desde la eternidad, y hoy se podría decir que todas las mónadas están programadas por Dios.

En lo que se refiere al conocimiento, el sistema de Leibniz excluye la pura empeiria como fuente del conocimiento. A la fórmula empirista según la cual no hay nada en el entendimiento que no haya estado antes en los sentidos, le añade Leibniz: excepto el entendimiento mismo, esto es, las ideas innatas y las estructuras del conocimiento.

La mera alienación de datos empíricos solamente ofrece resultados probables, mientras los resultados que se basan en el conocimiento de la razón son claros y correctos. Leibniz distingue entre las verdades de razón, que son necesarias y cuyo contrario es imposible, de las verdades de hecho, que son contingentes y cuyo contrario es posible. Por analogía con las verdades de razón y las verdades de hecho, Leibniz parte de dos reinos: el de las causas finales (el de las almas), y el de las causas eficientes (el de los cuerpos) que están armónicamente enlazados.

De igual manera enlaza el reino de la naturaleza con el de la gracia, esto es, la comunidad de seres espirituales y morales bajo la dirección divina. Dios actúa por doquier, pero los espíritus tienen una relación especialmente estrecha con Él a través de la participación consciente en la grandeza y bondad divinas. Así pues, Leibniz reconoce a Dios como arquitecto de la máquina del universo y como rey o monarca de la ciudad divina de los espíritus.

La existencia de Dios, en la que enseguida entraremos más a fondo, se demuestra además como consecuencia del principio de razón suficiente, al que Leibniz cita, junto al de no contradicción, como fundamentos de todo conocimiento racional. Esto significa que no 
puede hallarse ningún hecho verdadero o existente ni ninguna enunciación verdadera sin que haya una razón suficiente para que sea así, y no de otro modo, aun cuando esas razones nos puedan resultar, en la mayoría de los casos, como desconocidas.

La última causa suficiente tiene que ser Dios. Además Leibniz infiere de ello que solamente existe una substancia divina y ésta es perfecta.

Hay una infinidad de mundos posibles que, según su grado de perfección, podrían llegar a la existencia; pero siguiendo el principio de perfección, Dios ha creado solamente un único mundo existente que es el mejor de los mundos posibles, el cual tiene, en comparación con los demás, el mayor grado de adecuación interna.

La cuestión central de la Teodicea (1710) es la de cómo puede existir el mal en el mejor de los mundos posibles. Esta obra expone la justificación de Dios ante el mal, en el cual Leibniz distingue entre tres géneros: el mal metafísico, que surge de la condición de la criatura, donde todo lo creado es imperfecto, pues de lo contrario sería divino como su creador; el mal físico (el dolor, el sufrimiento), se justifica desde su función. Puede ser útil (para la conservación del individuo) o puede servir como castigo para conseguir mejoras; el mal moral, el pecado, que es la consecuencia de la libertad humana y el motivo de la redención cristiana.

Dios no ha querido estos males, sino que los tolera, siendo así que el bien los sobrepasa en mucho.

\section{La demostración de Dios por las verdades eternas}

El esquema básico de esta prueba para la demostración de la existencia de Dios está estructurado sobre un punto de partida, la verdad eterna; un núcleo central de la prueba, el principio de razón suficiente, y un punto de llegada, Dios como Ser Necesario.

a) Punto de partida: la verdad eterna.

Leibniz habla de "verdades eternas" como sinónimos de expresiones como "formas posibles absolutamente tomadas", "necesidades metafísicas", "ideas primitivas", "esencias" y "posibilidades". De lo que se trata en todas ellas de la misma realidad tomada desde distintos puntos de vista. Pero, ¿qué se entiende por verdades eternas propiamente?

Según Iwanicki se trata de “(...) esencias que no siendo creadas con sus existencias permanecen siempre en el estado de los posibles; son, pues, eternas y cuando un entendimiento eterno las conoce ellas constituyen verdades eternas" ${ }^{\prime 2}$. Las verdades eternas no son creadas por Dios y esto hace que sean comunes al entendimiento de Dios y al nuestro y también lo que permite hablar de las verdades eternas como esencias de las cosas, como posibilidades, como necesidades metafísicas o como verdad de razón.

\footnotetext{
${ }^{2}$ Iwanicki, J., Leibniz et les demonstrations mathématiques de l'existence de Dieu, Strasbourg 1933, pág. 282.
} 
Hay que saber que desde el punto de vista lógico, la verdad eterna se muestra con una validez objetiva en sí mismas, con un carácter absoluto, independiente, tanto del sujeto que las conoce como de la voluntad divina, es decir, ellas son verdad en sí y Dios las intelige porque existe y no porque quiere. No hay que olvidar que para Leibniz la lógica se confunde a veces con la realidad porque no distingue entre el uso lógico de los principios y el uso real de esos mismos principios. Por otro lado cabe decir que Leibniz identifica las verdades eternas con las verdades de razón, con la necesidad cuyo contrario es imposible (como decíamos en la introducción).

Desde el punto de vista metafísico, se destaca la naturaleza de las verdades eternas. Para Leibniz, las verdades eternas se equipara con los pensamientos divinos, y esto es precisamente lo que une el plano lógico con el ontológico. Esto es así porque “(...) la naturaleza de las cosas que se observan remite a un orden universal de perfección, que gobierna también las ideas que Dios tiene en sí y que tenía ya cuando se decidió a crear"3. El hecho de que las verdades eternas sean para Leibniz como los pensamientos de Dios justifica el innatismo leibniciano, pues Dios lo conoce todo de antemano y el hombre puede acercarse a su imagen, puede imitar el conocimiento divino.

También para Leibniz, - una academia en sí mismo, como lo llamaba Federico el Grande -, las verdades eternas son idénticas a los atributos divinos, “(...) que constituyen el inicio y la vía del conocimiento de la divinidad"4. La razón de esta identificación es que "estos atributos no son más que aspectos del Acto Puro; es el absoluto considerado bajo el aspecto relativo de nuestro espíritu" y porque existen unos principios comunes a las cosas divinas y humanas que tratan sobre la verdad y el ser en general. Este es el puente donde se unen el conocimiento que Dios tiene de la realidad con el que nosotros podemos tener de Dios. Ahora bien, las verdades eternas no están en las cosas como están en Dios, la diferencia radica en que en las cosas son limitadas e ilimitadas en el absoluto. Según Leibniz, esto explica que justifica que Dios no sea el causante del mal, porque "(...) éste proviene de la limitación esencial que tiene toda criatura aun en su estado de pura posibilidad",

Con todo, nos podríamos preguntar ¿dónde se encuentran las verdades eternas? Ante esta cuestión Leibniz asegura que se encuentran en Dios como sujeto último que posibilita que las verdades eternas se realicen, es decir, en Dios como sujeto fundante, dependen de una suprema inteligencia aunque para nosotros, limitados, no nos sea posible llegar a conocer con claridad de qué modo brotan de Dios.

b) Núcleo de la prueba: el principio de razón suficiente.

Uno de los núcleos más importantes de esta prueba es el principio de razón suficiente, pues este principio no sólo ayuda a conocer toda la realidad, sino que además, proporciona el valor geométrico a todas las pruebas que intentan demostrar la existencia de Dios. Este

\footnotetext{
${ }^{3}$ Cfr. Burgelin, P., Commentaire du Discours de Métaphysique de Leibniz, PUF, París 1959, pág. 84.

${ }^{4}$ Cfr. Von der wahren theologia mystica (1694- 1697), Guhrauer I, pág. 410.

5 Ángel Luis González., Las pruebas del absoluto según Leibniz, pág. 185.

${ }^{6}$ Cfr. Essais de Théodicée (1710), GP, VI, pp. 114-115, n 20.
} 
principio no tiene para Leibniz un concepto unívoco.

Para el filósofo que nos ocupa, "la razón última de todo es Dios"7, y esto nos indica que Leibniz se pregunta por la razón total y última de la realidad. En Dios es donde residen "las razones, los posibles que en la medida de su posibilidad darán lugar a las cosas contingentes en virtud de su grado de ser o de perfección que les capacita para ser realizadas si no hay nada que se oponga a ello" ${ }^{\text {. }}$

Dios es la razón suficiente de todas las verdades, pues el conjunto de todas las verdades eternas es el mismo entendimiento divino. Ahora bien este principio se puede considerar desde dos perspectivas: la lógica y la metafísica.

Desde el punto de vista lógico la naturaleza de este principio se expresa en la conexión del predicado con el sujeto, y esta conexión es la condición de posibilidad de su existencia. El contenido del predicado está ya de alguna manera inserto en el sujeto, esto es, que todo lo que será el sujeto en un futuro de alguna manera ya lo es en el presente. Esto modo lógico muestra la cercanía del Leibniz al principio de plenitud, y pone en marcha un determinismo lógico.

Antes decíamos que para Leibniz todo tiene una razón, y que la razón última de todo era Dios. Siguiendo este modo de proceder, parece que todo es cognoscible en principio o como pensaba Hegel, todo lo real es racional.

Desde la segunda perspectiva, la metafísica, este principio es fundante de lo real, y la negación del principio de razón suficiente, es para Leibniz, la destrucción de la distancia entre el ser y el no ser.

Leibniz identifica razón con requisito (aquello que si no es dado, la cosa no existe), condición o presupuesto adecuado. Para él, todos los requisitos son la razón suficiente. Por eso, todo lo que existe, existe porque tiene todos los requisitos, es decir, lo que existe es porque tiene una razón suficiente. La noción de causa se identifica con la noción de razón (causa sive ratio), "la causa es una razón real", es un modo determinado de la razón. Por ello, Ma . Socorro Fernández dirá que la razón se entiende como la condición necesaria y suficiente para la existencia de lo fundamentado por ella.

El absoluto es también razón de sí mismo, pero no como lo entendió Spinoza, sino porque contiene en sí todos los requisitos, todas las condiciones de su existencia que, al no encerrar contradicción, son posibles. De este modo el principio de razón suficiente es absorbido en el entendimiento del absoluto, pues se trata de una verdad eterna. Para $\mathrm{M}^{\mathbf{a}}$. Socorro Fernández, “(...). En este punto es donde la demostración de la existencia de Dios pierde fuerza en cuanto a su carácter probatorio ya que, aunque por una parte, el principio de razón suficiente es el que permite pasar del ámbito lógico de la no contradicción de las

\footnotetext{
${ }^{7}$ Cfr. De rerum originatione radicali (1697), GP. VII, pág. 305; Monadologie, (1714), GP. VI, pág. 614, nn. 44 y 45 .

${ }^{8}$ Cfr. Omne possible exigit existere (hacia 1700), GP. VII, pág. 194

${ }^{9}$ Cfr. Resumé de Métaphysique (1703), Couturat, pág. 553.
} 
verdades eternas como puros posibles al ámbito existencial, que hace que estas verdades tengan la razón de su existencia en un cierto ser necesario porque en sí mismas no la puedan tener, no se justifica el paso del ámbito noético al existencial" ${ }^{\text {10 }}$.

c) Punto de llegada.

Leibniz, más que en demostrar la existencia del absoluto, quiere resaltar su necesidad. "Si Dios no existiera todas las cosas serían simplemente imposibles" ", o dándole la vuelta a la frase, todo es posible porque existe Dios.

Ahora bien, ¿en qué radica la necesidad de la existencia del absoluto leibniciano? Ante esta pregunta, el filósofo de Hannover responde en su "Monadología" que el Ser Necesario es el ser $a$ se, en el que la Esencia encierra a la existencia o en el cual es suficiente ser posible para ser actual. Con ello quiere decir que en Dios la esencia no se distingue de su existencia y por eso se trata de un Ser Necesario. Su esencia envuelve a la existencia $^{12}$, es decir, parece que Dios es causa sui. Esa causa sui del absoluto leibniciano ¿es la misma que la Natura naturans de Spinoza?

A mi juicio, Leibniz se quiere salvar de toda posible cercanía al panteísmo, por ello, salva la trascendencia divina, pues el Dios leibniciano no es un Dios intramundano sino que es la mónada perfecta, y, como toda mónada, única y singular. Se trata de la Monas monadum, infinita, y por tanto diferenciada de todas las demás mónadas que son finitas. Según la posición de $\mathrm{M}^{\mathrm{a}}$. Socorro Fernández, la trascendencia divina no está muy clara en el pensamiento leibniciano, “(...) en Leibniz no queda muy claro al final cuál sea la distancia que separa al Creador de las criaturas. Por un lado, para defenderse del panteísmo se esfuerza por establecer una diferencia: las cosas creadas llevan la huella del creador, pero no son Dios; con la actualización, se ponen en la existencia, unas cuantas verdades eternas en virtud de su perfección y de su composibilidad, pero no son todo lo que Dios es, porque Dios es más. Ahora bien, este ser más, es una distinción de grado, una distinción cuantitativa. Dios es más porque tiene más, pero no es completamente otro pues de otro modo no podría conocerse nada",13.

La trascendencia se ve más claro cuando Leibniz subraya que la esencia de Dios no se puede llegar a comprender en su totalidad por un entendimiento limitado.

Ahora bien, si antes decíamos que todo es cognoscible, ¿cómo ahora no podemos comprender a Dios? Parece que esa incomprensión sólo tiene lugar si es total, no podemos comprender, abarcar a la totalidad de se ser, pero conocemos sus atributos, pues si Dios es la razón última de las cosas es preciso entonces que sea inteligente y absoluta y perfecta en

\footnotetext{
10 Ángel Luis González, Las pruebas del absoluto según Leibniz, pág. 197.

${ }^{11}$ Monadologie (1714), GP. VI, pág. 614, no 43.

12 "Solus Deus est Ens per se, seu absolute necesarium, cuius essentia scilicet involvit existentiam". De libertate (nov.1677), GRUA I, pág. 274

${ }^{13}$ Ángel Luis González, Las pruebas del absoluto según Leibniz, pág. 199.
} 
potencia, sabiduría y bondad, ya que ella se adapta a lo que es posible. El entendimiento divino, las verdades eternas o el mismo principio de razón suficiente es la fuente de las esencias, mientras que su voluntad es el origen de las existencias.

Pero en este Dios construido por Leibniz prima más la esencia que la existencia, pues su esencia contiene todas las perfecciones. Puede con ello deducir todos los atributos divinos porque "si Dios es posible, existe necesariamente, y si existe necesariamente todas las perfecciones le son propias porque las posee todas de modo necesario"14.

Se trata pues de un Dios que es razón, un ser constituido por el conjunto de las verdades, de razones, de requisitos de todas las cosas tanto posibles como existentes, que son o se identifican con el entendimiento divino.

La conclusión de la prueba por las verdades eternas desembocan en un Dios que es Sabiduría, pues Él lo conoce todo, Pero, ¿dónde queda su voluntad, que al fin y al cabo es la que otorga la existencia de las cosas? La voluntad juega un papel secundario, pues ella elige entre los posibles lo que es mejor, y lo que hace que el mundo en el que vivimos no sea todo lo que Dios es, sino fruto de una elección divina. Por eso este mundo es el mejor de los posibles.

\section{La armonía preestablecida para demostrar la existencia de Dios.}

En este argumento tan original de Leibniz, se parte de la observación en la naturaleza de un hecho: la armonía que existe en el mundo, en la relación de las mónadas, y la actividad interior que hay en cada una. Ante este hecho, el de la armonía, se le aplica el principio de razón suficiente $\mathrm{y}$, posteriormente, se llega a Dios como causa última y principio radical del movimiento y de la teleología del universo.

"El argumento por la armonía preestablecida accede a Dios como causa común, como fuente y origen de la armonía con la que las substancias se relacionan, y por la que, en definitiva, existen" $"$.

a) Punto de partida: la armonía preestablecida.

El mismo concepto de armonía nos lleva a pensar de antemano que se trata de un equilibrio, de una adecuada proporción entre las partes. Pero la armonía de la que habla Leibniz viene de una intuición. No se trata de un vago sentimiento subjetivo o de una armonía basada meramente en términos de equilibrio, sino más bien, se trata de una armonía metafísica, universal, pues además de explicar la relación que media entre alma y cuerpo, y la relación de todas las mónadas, también explica la relación de las causas eficientes y finales y la relación entre el mundo de la naturaleza y el mundo de la gracia.

\footnotetext{
${ }^{14}$ Ibídem, pág. 201.

${ }^{15}$ Ibídem , pág. 234.
} 
Esa armonía solo está presente en Dios, pues ella es trascendente respecto al orden de lo creado.

García Morente explica este concepto con estas palabras: “(...) cuando Dios crea las mónadas pone en cada una de ellas la ley de la evolución interna de sus percepciones. Por consiguiente, todas las mónadas que constituyen el universo están entre sí en una armónica correspondencia; correspondencia armónica que ha sido preestablecida por Dios en el acto mismo de la creación; en el acto mismo de la creación cada mónada ha recibido su esencia individual, su consistencia individual, y esa consistencia individual es la definición funcional, infinitesimal de esa mónada. Es decir, que esa mónada desenvolviendo su propia esencia, sin necesidad de que de fuera de ella, desenvolviendo su propia esencia, coincide y corresponde con las demás mónadas en una armonía perfecta del todo universal" ${ }^{\prime 16}$.

No se trata de una armonía sin más, sino de una armonía que está preestablecida, esto es, que es a priori al movimiento de los seres, "pues en virtud del principio de razón suficiente no cabe ningún movimiento si no está previamente ordenado en una dirección determinada" $" 17$. Por tanto, este concepto es a la vez un principio universal y a priori que determina el ser de lo creado.

Leibniz define este concepto como “(...) la perfección de los pensables, en cuanto que son pensables. Hay armonía cuando muchas cosas se reducen a una sola. Pues donde no hay variedad no hay armonía. Del mismo modo, donde hay variedad sin orden, sin proporción, no hay armonía. De este modo, resulta patente que cuanto mayor sea la variedad y la unidad en esa variedad, tanto mayor será la armonía" ${ }^{\prime 18}$, y en otra ocasión la define como una cierta simplicidad en lo múltiple. Pero es necesario saber que este concepto no lo emplea cuando se habla de las partes, sino que se refiere a la totalidad.

Leibniz no se queda en el monismo de Spinoza, sino que mantiene también la multiplicidad sin negar, a la vez, la unidad, pues la armonía como la unidad en la variedad de un todo es el puente que enlaza esos dos principios. Entre otras cosas, por esto también salva la trascendencia, pues de otro modo se quedaría en el inmanentismo propio de los pensadores panteístas.

b) Desarrollo de la prueba.

Ya hemos dicho que el concepto o principio universal de la armonía preestablecida es a priori. Este modo de ser a priori se de este principio se explica sabiendo que en la lógica leibniciana el predicado está contenido en el sujeto. Por eso las mónadas son incomunicables, pues ellas ya son lo que serán, en ellas habita una ley interna que desarrollará el modo de ser de esa mónada. Esa ley interna que se encuentra en todas y en cada una de las mónadas se articula por la armonía preestablecida. Esa armonía es la protagonista de sincronizar y organizar todo el desarrollo posterior de todas las mónadas.

\footnotetext{
${ }^{16}$ Manuel García Morente, Lecciones preliminares de filosofía, pág. 167.

${ }^{17}$ Ángel Luis González, Las pruebas del absoluto según Leibniz, pág. 238.

${ }^{18}$ Gr. Inéd., pág. 12.
} 
En palabras de J. Jalabert, la concomitancia de todas las substancias, que hacen que se correspondan, dando lugar a la apariencia de una interacción, constituye lo que Leibniz llama su armonía preestablecida.

Ahora bien, este principio universal y a priori, ¿tiene alguna causa? Esta pregunta concluye en una causa universal que debe ser inteligente y dotada de una ciencia máxima. Esta causa, la de la armonía preestablecida, es la que explica el desarrollo de las mónadas en su conjunto y no la ley interna que hay preestablecida en ellas. "Hay, pues, una finalidad superior, a la cual todas las otras se subordinan, y esta finalidad trascendente debe ser inteligente y omnisciente" ${ }^{\text {"19 }}$.

Además, este orden que está en presente armonía y que posee un carácter universal, exige un sujeto. José $\mathrm{M}^{\mathrm{a}}$. Aguilar lo dice de un modo más neto: "Si cada una de las mónadas constituye un punto de vista sobre la totalidad, y a la vez no puede comunicarse de ningún modo con las demás, es preciso que exista una causa universal, que garantice ese orden preestablecido: no un punto de vista más, sino la totalidad misma asumida en perfecta autoconciencia" ${ }^{20}$. Estas palabras expresan realmente el núcleo de la prueba de la existencia de Dios a partir del principio universal de la armonía preestablecida.

Este principio puede ser una identificación con la existencia cuando leemos una frase que Leibniz pronuncia antes de 1680: "existere nihil alium est quam harmonicum esse", es decir, existir no es otra cosa que ser armónico. Esto es lo propio de un racionalista exacerbado, que no puede consentir el desorden, el desequilibrio tanto en el plano lógico como en el metafísico. De la misma manera podríamos afirmar lo contrario de tal afirmación, esto es, que nada puede existir si está desordenado, sino está en armonía.

En definitiva, la armonía preestablecida tiene por causa a Dios (pues todo tiene una razón suficiente y la última razón siempre es Dios), pues Dios al crear la totalidad de las mónadas, cada una con su ley interna, las ha creado en armonía preestablecida, y entonces sin que haya una intercomunicación de las substancias, de hecho, siguiendo cada una ciegamente su propia ley, resulta la armonía universal del todo.

Resumiendo con otras palabras en paralelo: la finalidad está en cada mónada y adquiere diversas formas de las que la más conocida es la apetición (tendencia a pasar de una percepción a otra). Esta finalidad se da en cada mónada, cada una tiende a su fin por propia iniciativa. Las mónadas van variando sucesivamente no por influencia exterior, sino que varían internamente. Esta tendencia a la finalidad es armónica, pues hay una correspondencia entre la tendencia de cada una y ésta es propiamente la armonía preestablecida.

\footnotetext{
${ }^{19}$ Ángel Luis González, Las pruebas del absoluto según Leibniz, pág. 243.

${ }^{20}$ Ibídem, pág. 244.
} 
c) Punto de llegada: Dios armónico y armonizante.

Esta misma armonía es tan poderosa que incluso el mismo Leibniz la llega a identificar con Dios: "Puedo demostrar que hay una razón última de las cosas que consiste en la armonía universal, es decir, Dios (ratio ultima rerum seu harmonia universalis, id est Deus" $"$.

Pero no solo se trata de una identificación, sino también en que Él mismo consiste en armonizar el universo, es pues Dios una armonía que armoniza, una armonía originaria y originante (si cabe hablar así). Para J. Echeverría, Dios existe, y no es sino la armonía o concordancia entre los distintos individuos o mónadas; y no sólo la armonía entre sus respectivas percepciones, sino también entre sus actos: proyectos comunes, etc. La armonía es la misma vida de Dios, y esto se asemeja al Dios aristotélico cuando el estagirita deducía como atributo divino la misma vida de Dios.

La armonía preestablecida no debe interpretarse como si Dios armonizase todas las mónadas en el momento de crearlas, sino que crea unas sustancias que en virtud de su propia naturaleza están ya armonizadas en su estado de mera posibilidad porque si no estuvieran armonizadas siendo posibles, cambiarían cuando ya estuviesen creadas.

Las mónadas creadas, por su limitación, no pueden conocer en su amplitud a la Monas monadum, sólo pueden llegar al creador a través de las verdades eternas y del conocimiento de la armonía como principio universal y a priori.

Precisando y concluyendo, podemos decir que este argumento postula la existencia de Dios como condición de inteligibilidad. Para Leibniz la finitud se explica por el carácter limitado de todo espíritu creado, y la infinitud exige una instancia superior donde la posesión intelectual de todo lo posible se dé de un modo total.

\section{El argumento de la contingencia.}

Esta prueba pretende demostrar la existencia de Dios de un modo a posteriori. Dios existe porque existen otros seres que son contingentes y que no pueden tener su razón suficiente en sí mismos sino en un ser necesario, el cual tiene en sí la razón de su existencia.

El origen de esta prueba surge por la siguiente pregunta, ¿por qué existen las cosas y no otras?, esto es, ¿por qué existen las cosas como son pudiendo ser de otra manera? Este es realmente el motor de la prueba, su origen, al que, a través del principio de razón suficiente se llegará a la existencia de un Ser necesario que ha querido crearlas a su antojo, es decir, no es que las haya creado sin racionalidad, sino que la causa o el motivo de la creación es su misma voluntad libre y omnipotente.

\footnotetext{
${ }^{21}$ G. I, pág. 61.
} 
a) El punto de inicio: los seres contingentes

Para el filósofo de Hannover, la contingencia se define por vía negativa, esto es, aquello que no es necesario, "contingens seu Non-necesarium est", fundamenta esta prueba del argumento cosmológico, pues el mundo no sólo podría ser de otra manera sino que sería posible que incluso no existiera. Es a posteriori porque comienza por el hecho mismo de lo contingente.

Por el contrario el sistema de Spinoza consistía en lo contrario, es decir, en que no hay nada contingente, sino que todo, el Uno-Todo es necesario, y por esta misma razón, un necesitarismo radical y absoluto, niega la posibilidad de que pueda haber una finalidad. La finalidad es para el holandés el hijo bastardo de la ignorancia.

Para no caer en el necesitarismo spinociano Leibniz recurre a las cosas posibles en su propia naturaleza, a aquello que ni es ni será. “(...) su fundamentación de la contingencia en el hecho de que la elección divina mantiene la posibilidad de otros mundos posibles es insuficiente, pero la posibilidad de la elección permanece y esto es lo que explicará y fundará la contingencia"23.

Lo contingente es el posible actualizado, que es el mejor de los posibles, aquello que aun siendo imperfecto es lo mejor entre los posibles, lo que no es contradictorio. "Lo posible es todo aquello que no implica contradicción. Las realidades actuales no son sino los mejores de entre los posibles. Sin embargo, lo que es menos perfecto, no es por ello mismo imposible; hay que distinguir entre lo que Dios quiere y lo que Dios puede: quiere lo mejor, puede todo" ${ }^{, 24}$. De esta manera Leibniz distingue entre lo posible y lo real, entre lo necesario y lo contingente.

La definición de Leibniz de lo contingente como aquello cuyo opuesto no tiene contradicción, lo posible, implica que lo que se entiende por contingente no incluye el plano de la metafísica, sino el de la lógica. Se trata de una posibilidad lógica que desembocará sin una razón en una posibilidad metafísica. Pues, por otro lado, atribuye lo necesario a la Monas monadum, al Creador y lo contingente a la mónada común, a la criatura. Pues, si en Dios la esencia es la existencia, le compete ser necesariamente. Sin embargo en las criaturas la esencia no se confunde con la existencia, su existencia no se sigue de su misma esencia, y, por lo tanto, no se trata de un ser necesario sino de un ser contingente. Pero esta misma conclusión ya no es meramente lógica sino metafísica ${ }^{25}$.

\footnotetext{
${ }^{22}$ G. VII, pág. 108.

23 Ángel Luis González, Las pruebas del absoluto según Leibniz, pág. 128.

${ }^{24}$ G. M. III, pág. 574.

${ }^{25}$ ¿Hay confusión de planos entre lo lógico y lo metafísico? Ante esta pregunta Fuertes piensa que Leibniz distingue entre una contingencia metafísica y una contingencia de las verdades, donde en la fundamentación de aquélla se introduce en el terreno lógico como base y condición de la contingencia metafísica.
} 
Ahora bien, parece que el principio de razón suficiente no interviene en el ámbito de la contingencia, pues como argumenta Andrés Fuertes, “(...) lo que no existe de modo necesario - y según las definiciones antes apuntadas, en esto consiste estrictamente la contingencia - no tiene en sí una razón de su existencia. (...) Las esencias posibles no tienen en sí mismas, pese a su tendencia a la existencia, una razón de ésta, sino que la razón suficiente ha de ser buscada en la elección divina sobre la que actúa su potencia operativa (en la contingencia se mezclan posibilidad, entendimiento y voluntad divinos) y lo convierte en actualmente existente, o lo que es lo mismo, en contingente" ${ }^{26}$. Lo que ha hecho Leibniz es que a la posibilidad lógica se le añade la ausencia (valga la expresión) del principio de razón suficiente, y en esto radica la contingencia como tal. Es decir, Leibniz fundamenta lo contingente en la posibilidad, en la no contradicción. Parece como si Leibniz insinuase una identificación de lo posible con lo contingente, pero esto no es así porque se trata más bien de “(...) dos modalidades distintas del ser, al menos, con la distinción de fundamentado y fundamento. Mientras que el posible está por la esencia, lo contingente designa la existencia, lo actual..." ${ }^{27}$, de esta manera lo contingente se explica por referencia a lo posible, el posibles es, en definitiva, un antecedente de lo real. Si en lo contingente no aparece el principio de razón suficiente, sí comparece el principio de conveniencia o de lo mejor: "La verdadera causa por la que existen ciertas cosas más bien que otras ha de derivarse de los decretos libres de la voluntad divina, el primero de los cuales es querer hacer todas las cosas del mejor modo posible" ${ }^{28}$. Lo que no parece muy claro en lo que llevamos visto hasta ahora, es, a mi modo de ver, qué es lo que sucede con el principio de razón suficiente y el principio de lo mejor o conveniente. Según Andrés Fuertes, siguiendo la frase de Leibniz: "Es preciso que Dios haya elegido lo mejor, ya que él no hace nada sin actuar según la suprema razón" 29 , el principio de lo mejor, el que se le aplica a los contingentes, es una consecuencia del principio de razón suficiente.

Por otro lado parece que Leibniz evade una argumentación más convincente en la demostración de lo contingente o lo existente, pues en un momento llega a escribir que la verdad acerca de lo contingente es la imposibilidad de su demostración, "En las verdades contingentes, aunque el predicado esté comprendido en el sujeto, no obstante jamás pueden ser demostradas, ni jamás la proposición puede transformarse totalmente en una igualdad o identidad, sino que la resolución procede al infinito, y sólo Dios ve, no el fin de la resolución, puesto que ella no la tiene, sino la conexión de los términos o la implicación del predicado en el sujeto, ya que él ve todo lo que está comprendido en la serie" ${ }^{\text {"30 }}$. Esto quiere decir que lo que fundamenta al ser contingente, la radix contingentiae, es el infinito.

\footnotetext{
${ }^{26}$ Ángel Luis González, Las pruebas del absoluto según Leibniz, pág. 122.

${ }^{27}$ Ibídem, pág. 124.

${ }^{28}$ G. VII, pág. 309-310.

${ }^{29}$ G. VI, pág. 107.

${ }^{30}$ C.L., pág. 211.
} 
b) El principio de razón suficiente como condición de la prueba. Dios como Causa sui.

El objetivo que pretende Leibniz es asegurar a la existencia contingente un fundamento que sea necesario, o a la inversa, demostrar la existencia de Dios mostrando (no demostrando) el origen radical de las cosas, lo contingente.

Este principio no nos induce sólo a considerar la posibilidad como fundamento de lo contingente, sino que además nos dirige a Dios, que es la razón última y suficiente de la existencia de lo contingente. Por tanto, dicho principio tiene un carácter trascendental, pues se aplica a todo, puesto que todo tiene causa (sive ratio), incluso la misma existencia de Dios que fundamenta las demás tiene que tener una razón suficiente, el fundamento también está fundamentado, lo que pasa es que ese fundamento depende, en Dios, de sí mismo. Por tanto, Dios es causa sui, Dios existe por su esencia.

La demostración de este argumento estriba en que todo lo que es tiene todos los requisitos o razones para existir, y puestos todos los requisitos, la cosa existe, de lo contrario, habría una ausencia de algún requisito. Ahora bien, si resulta que todas las razones son razones suficientes, todo lo que es tiene que tener necesariamente una razón suficiente.

Causa y razón son exactamente lo mismo, al igual que requisito o condición necesaria $^{31}$ para la existencia de lo existente.

\section{c) Conclusión de la Prueba}

La conclusión de esta prueba es que existe un ser necesario que es el que da razón del ser contingente. Leibniz lo radica así: si algo existe, Dios también existe como razón de ese algo y razón de todos los seres. Dios existe como el ser a se, como razón de sí, le es esencial existir, es, en definitiva y como ya hemos repetido causa sui.

Con todo, la prueba del argumento cosmológico o de la contingencia al preguntarse por la razón suficiente de las cosas contingentes, esto es, al preguntarse por qué hay algo y no más bien nada ${ }^{32}$, responde negando que esa razón suficiente no puede encontrarse ni en una cosa particular (puesto que son contingentes), ni en el mundo en su conjunto, ni tampoco en una serie indefinida de cosas particulares (pues la serie sigue siendo contingente). Esa razón suficiente sólo puede encontrarse en un ser extramental, necesario que otorgue esa razón suficiente de lo contingente.

\footnotetext{
${ }^{31}$ En esta identificación se separa Leibniz de la tradición clásica, pues la condición no era la causa sino el requisito del ejercicio de la causalidad.

${ }^{32}$ Esta pregunta es la misma que se hace Heidegger al inicio de su metafísica aunque con otro sentido diferente.
} 


\section{La prueba ontológica}

Parece ser que Leibniz quiso completar el argumento ontológico cartesiano. Para Leibniz el argumento del francés necesita perfeccionarse. El argumento cartesiano sería concluyente sólo si se demuestra que Dios es posible porque, de lo contrario podrían deducirse contrariedades serias.

Descartes tenía una idea innata pero no actual de Dios, sin embargo, el filósofo de Hannover tiene una idea innata pero virtual del absoluto. Para Leibniz, la idea de Dios no está totalmente formada en nuestro entendimiento de un modo actual, sino que nuestro entendimiento tiene la fuerza de formar esa idea a la manera como en un bloque de mármol está diseñada una figura. Y esta idea innata que posee Leibniz es la idea de un ser necesario.

La crítica de Leibniz a Descartes es que éste no ha probado que la idea de un ser omniperfecto es posible, es decir, no contradictoria. Mientras que Descartes partía de la idea de Dios, Leibniz quiere probar la posibilidad de la idea de la que se parte. Piensa Leibniz que no vale decir que la idea de Dios es posible porque nadie ha demostrado que es imposible ya que se trata de una prueba negativa de la posibilidad. Hay que probar pues una que sea positiva.

Para Descartes la idea de Dios es verdadera porque es una idea clara y distinta. Pero con esos criterios, piensa Leibniz, no se puede llegar a nada porque son unos criterios meramente subjetivos, relativos. Tienen que ser al menos unos criterios intersubjetivos. Por eso Leibniz manifiesta que Descartes cae en un psicologismo vulgar. “(...), Leibniz matiza aún más su postura al señalar que elevar a principio normativo una situación de facto - la mera validez de lo dado clara y distintamente -, no es sino un vulgar psicologismo"33.

Decir que el ser omniperfecto es posible no implica contradicción porque la perfección encierra algo positivo y, si no entraña nada negativo, tampoco encierra contradicción alguna porque la contradicción resulta de afirmar y negar a la vez lo positivo y lo negativo, pero no de lo positivo solo.

No hay de las perfecciones incompatibilidad, no hay pues contradicción y, por tanto, es posible. También es posible la idea de Ser necesario. Para Leibniz “(...) estos argumentos son válidos si sucede que el Ente perfectísimo o el Ente necesario es posible" ${ }^{34}$.

Parece que el argumento propiamente sería el siguiente: Si el ser es necesario es posible entonces existe. Es posible, luego existe. No encierra contradicción porque si no existiera él, no existiría nada; es así que existen muchas cosas, luego existe él.

Las palabras "Ser perfectísimo corresponden a una idea verdadera si dicha idea es

\footnotetext{
${ }_{33}^{3}$ Ángel Luis González, Las pruebas del absoluto según Leibniz, pág. 295.

${ }^{34}$ Animadversiones (1691-7), art. 14, G.P. IV, pág. 359.
} 
posible, o si su contenido no es contradictorio, o si de ella puede darse una definición real, es decir, aquella definición en la que consta que la cosa es posible, o que tiene esencia" ${ }^{35}$.

Es obvio que en la filosofía leibniciana no se puede prescindir de una posibilidad lógica. Lo que queda es el paso de una posibilidad lógica a la posibilidad de la existencia. Ahora bien, ¿qué es la posibilidad? Según Zubiri se trata de un poder ser siendo ese poder una praetensio ad existendum, posee un contenido que se identifica totalmente con el concepto objetivo; es anterior a la realización fáctica, -esto es, a su existencia contingente -; y por ser anterior debe entenderse que es fundamento de la realidad.

De los dos posibles leibnicianos, el puramente lógico y el real, el segundo es llamado existente virtual, “(...) por cuanto tiene una existencia peculiar: incluye entre sus determinaciones una exigencia que llegará a cumplirse en su existencia real”, ${ }^{, 36}$.

Para Leibniz todo lo que es posible tiene una exigencia a la existencia, pero esa exigencia es distinta en los seres, no es unívoca sino que dependen del grado de perfección que tengan. “(...) la exigencia de existencia es fruto de la cantidad de esencia o perfección, no de la lucha de los posibles; esto es consecuencia de aquello, y no al revés",37. Por eso, la exigencia del ser divino es la exigencia de una esencia omniperfecta y no puede quedarse en mera inclinación o exigencia a existir porque es la de un ser que encierra toda perfección y la existencia para Leibniz es una perfección. Por eso debe ser actualizada, pues de lo contrario sería la exigencia de una esencia absolutamente perfecta. Pero sólo Dios tiene este privilegio: si es posible es menester que exista, tiene que existir, con lo cual existe.

El razonamiento que sigue Leibniz es el siguiente:

El Ser necesario, si es posible, existe. Si no hay Ser necesario no hay posible (lo real de la posibilidad carece de fundamento). Pero hay algo posible. Luego el Ser necesario existe.

Este razonamiento no es propiamente la demostración ontológica pues no sólo mira a Dios, sino también a lo posible distinto de Dios. “(...) la mera no-contradicción señala la aptitud para existir, el ser meramente posible; mas, por no significar la nada, sino algo, en sentido meramente extensional, y en la medida en que delimita un cierto contenido de esencia, ya no significa sólo mera posibilidad sino perfección, que implica la mayor o menor conveniencia, según la mayor o menor perfección respecto a la existencia fáctica" ${ }^{38}$.

Para Leibniz, según lo visto, parece que lo real es la esencia (perfección), las realidades ideales. (Este idealismo racionalista se observa más nítidamente en el argumento modal). La exigencia de existencia se aplica a estas realidades ideales. Dicha exigencia es fruto de la cantidad de esencia (perfección). "La posibilidad real se contempla directamente en Dios al considerar su esencia, su perfección infinita, que no necesita para existir sino ser posible, y no ser el mejor entre todos los posibles, ni ganar en la batalla de los posibles; tampoco necesita ser exigido como fundamento por el resto de los posibles,

\footnotetext{
${ }^{35}$ Cfr. Carta a Foucher (XI-XII. 1686), G. P. I, pág. 384.

${ }^{36}$ Ibídem.

${ }^{37}$ Ángel Luis González, Las pruebas del absoluto según Leibniz, pág. 356.

${ }^{38}$ Ibídem, pág. 335.
} 
que se ven reducidos a la nada si no hay algo real más allá de su simple posibilidad; ni tan siquiera precisa ser composible con todo mundo posible; sino sólo ser posible ad intra. Por la misma naturaleza de la argumentación, en el argumento ontológico, Dios no existe por ser composible, sino sólo posible ${ }^{39}$.

\section{El argumento modal.}

El punto de partida de esta nueva argumentación derivada del argumento ontológico es el Ser necesario, es decir, el ser de cuya existencia se sigue necesariamente de su esencia. No parte pues del Ser perfecto como en la prueba anterior, sino del Ser necesario, al que deberá explicar Leibniz que ese ser también es posible.

La posibilidad de Dios y su existencia actual son inseparables. Esta es la dificultad que se plantea en este argumento. La aclaración de este es, a mi juicio, porque en Leibniz la posibilidad y la esencia es lo mismo, y, por tanto, si Dios es definido como el ser del cual es esencial existir, es decir, si Dios es necesario (que exista), entonces no tiene ningún sentido que no exista, luego existe. Ahora bien, ¿dónde radica la posibilidad de Dios? En mi opinión si lo posible es por otro, y Dios es posible, lo que salvaría a este argumento es la noción de causa sui, pero siendo ese sui no más que otro que es Él mismo, cosa que parece imposible o al menos un intento desesperado de llegar a Dios. Pero ese otro "(...) en la categoría de mero posible son los principios de la inteligibilidad. Y el conjunto de los posibles es así mismo ser por otro. Por consiguiente, el Ser necesario forzosamente es posible, porque los posibles no pueden ser sin razón, y esa razón no puede ser un ser imposible. Tiene que ser un Ser por sí, lo que permite la inteligibilidad, eso que se llama el Ser necesario" ${ }^{\prime 40}$.

Ser necesario es la conclusión del argumento cosmológico o de la contingencia, y, por lo tanto, se podría decir que también ese Ser necesario es la razón suficiente de los contingentes, de los posibles, de lo que no muestra signo alguno de contradicción en ellos mismos. Si no hay un Ser necesario, no es posible que haya ser posible alguno, pero ya se demostró en el argumento de la contingencia que el Ser necesario existe, y, por lo tanto, también habrá que decir que los posibles existen. Y, por último, si existen los posibles es por una razón suficiente, a saber, Dios como razón última de todo lo que existe.

Con el argumento modal la sospecha de un posible idealismo, además de su racionalismo exacerbado, es más patente pues los posibles son realidades ideales, en su mundo ideal, un mundo que a fin de cuentas es el entendimiento divino. Esas realidades ideales, los posibles, los contingentes existirán o no por la voluntad divina. Este modo de ser de los posibles, a saber, realidades ideales o esencias, hace necesaria la existencia de Dios. (Esta última deducción no está argumentada por el espacio que ya he dedicado anteriormente). Lo que quiere mostrar el argumento modal es el paso de las esencias a las existencias, de lo ideal a la realidad.

\footnotetext{
${ }^{39}$ Ángel Luis González, Las pruebas del absoluto según Leibniz, pág. 336.

${ }^{40}$ Ibídem, pág. 403.
} 
Se podría decir que para Leibniz si hay ser posible, hay Ser necesario, esto es, si es imposible el Ser necesario, es imposible el posible. Ahora bien, existen los posibles, y, por tanto, el Ser necesario es posible. Lo que no se ve claro es dónde se ve que existen los posibles. Esta es la cuestión que, en mi opinión Leibniz no muestra o demuestra del todo. 